\title{
Metadomotic optimization using genetic algorithms
}

\author{
Salvador Merino슬 Javier Martínez ${ }^{1}$, Francisco Guzmán² \\ 1 Department of Applied Mathematics \\ ${ }^{2}$ Department of Electrical Engineering \\ University of Málaga, Spain \\ smerino@uma.es_jmartinezd@uma.es_f_guzman@uma.es
}

\begin{abstract}
New technologies applied in domotic allow us to extract plenty of data about the usual behavior of occupants in any installation. Discipline that works with these data for the pursuit of new knowledge is called Metadomotic.

To achieve this learning and relationships between different data, we make use of the tools provided by artificial intelligence. Today the use of these techniques in solving problems is fully extended. Among the best known we will focus on the application of genetic algorithms, technical halfway between biology and mathematics, to try to resolve the issues raised in this paper.

This article proposes the classification of domotic parameters to optimize an objective function. In a nutshell we will try two possible applications:

1. The minimization of energy consumption through the classification of the parameters of use and consumption coefficients, inherent to each user and device

2. The maximization of industrial production through the influence of environment parameters

Once established several basic suboptimal solutions, they will be combined randomly, through the crossover, mutation and cloning, to try to find the optimal.
\end{abstract}

\section{Keywords}

Domotic, metadomótic, energy efficiency, artificial intelligence, genetic algorithms 